\title{
Small wind, big potential: HAWT design case study
}

\author{
Filip Grapow ${ }^{1, *}$, Dominika Raszewska $^{1}$, Rafat Skalski ${ }^{1}$, Jeremiasz Czarnecki ${ }^{1}$, Katarzyna Telega $^{1}$, Marcin $_{\text {Miller }}{ }^{1}$, \\ Pawet Rogowski ${ }^{1}$ and Matgorzata Prociów ${ }^{1}$ \\ ${ }^{1}$ Institute of Turbomachinery, Lodz University of Technology, 90 - 924 Lodz, 219/223 Wolczanska Street, Poland
}

\begin{abstract}
In this paper the project of a small wind turbine for urban application has been described. The project of a horizontal small wind turbine presented in this paper was made for the purposes of taking part in ISWTC, but the main target was to develop a turbine for urbanized regions starting in conditions of low wind speed. In this paper a description of aerodynamic and mechanical design are presented; also, control and safety systems are discussed. This turbine has the potential to become a cheap energy generator for household use and can be a competitor of vertical small wind turbines.
\end{abstract}

\section{Introduction}

World energy demand is growing drastically every year. Conventional energy sources are no longer sufficient for electricity consumption and renewable energy sources, like wind power or photovoltaics, are becoming an important part of the energy mix [1]. Moreover, in the energy systems all over the world there are more and more "micro installations" which are power sources below 40 $\mathrm{kWp}$ [2]. A lot of people want to have their own power plant in their yard or on the roof of their houses so the interest in small wind turbines is now rocketing [3]. The International Small Wind Turbine Contest can be considered as proof of this statement.

The International Small Wind Turbine Contest is held by NHL University of Applied Sciences, Leeuwarden, Netherlands [4]. The goal of this contest is to design and create a SWT (Small Wind Turbine), which has optimal power production in a pre-specified wind regime. In assessment not only generated power is important but also safety during operation, cost efficiency, emergency braking systems and even the visual aspect of the design.

This paper presents the project of GUST (Generative Urban Small wind Turbine) Team from Lodz University of Technology and consists of technical design, aerodynamic design and safety and control system description.

\section{Technical specification}

The members of the GUST team faced the real-life problem, where, on the one hand, the design of a small wind turbine should be innovative and efficient in order to cope successfully with low wind speeds frequently encountered onshore at hub height just a few meters above ground level, but, on the other hand, because of economic aspects and universality the prototype should not be complex. The team decided to construct and optimize a traditional Horizontal-Axis Wind Turbine (HAWT) [5].
After a sequence of numerical simulations of aerodynamic performance and in-depth analysis of the proposed designs from mechanical point of view, the final three-bladed upwind configuration was chosen (see Fig. 1). A short summary of its key operational parameters is presented in Table 1.

At this point it was impossible to predict the exact rated wind speed of the designed wind turbine so, as explained in the following sections, a value of $8.4 \mathrm{~m} / \mathrm{s}$ was determined on the basis of calculations done within Simple Load Model analysis proposed in IEC 61400-2 standard [1]. The resulting design parameters like power and torque correspond to this estimated value of wind speed and determined numerically optimal tip speed ratio (TSR).

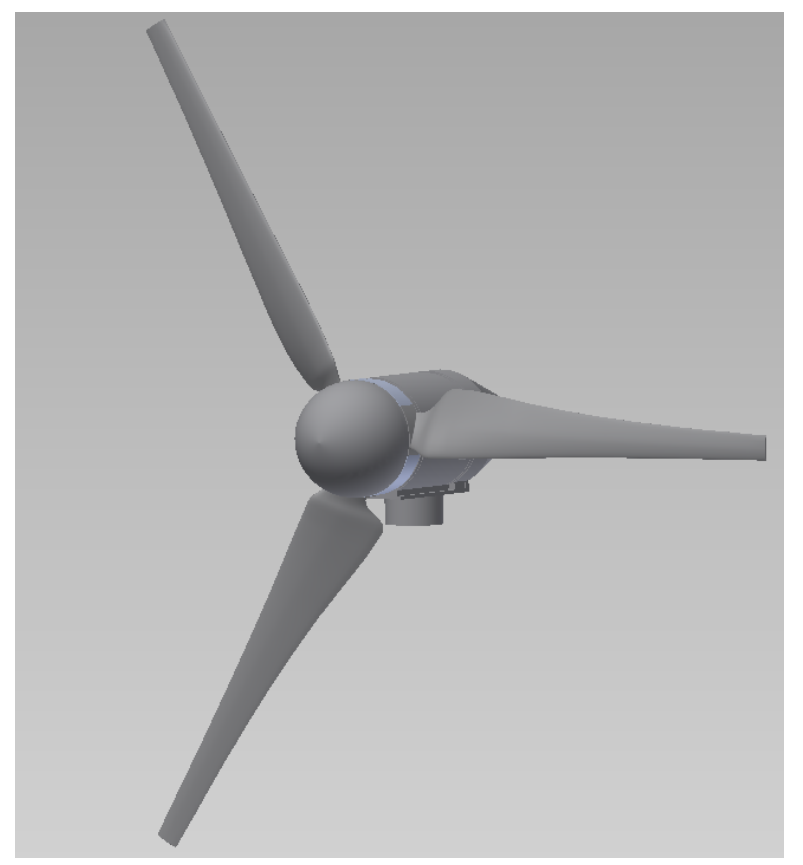

Fig. 1. 3D CAD model of the designed small wind turbine.

\footnotetext{
* Corresponding author: filip.grapow@p.lodz.pl
} 
Table 1. Summary of the characteristic features of the designed small wind turbine.

\begin{tabular}{|l|c|c|}
\hline \multicolumn{1}{|c|}{ Parameter } & Value & Unit \\
\hline Rotor diameter & 1.6 & $\mathrm{~m}$ \\
\hline Rated wind speed & 8.4 & $\mathrm{~m} / \mathrm{s}$ \\
\hline Cut-in wind speed & 3 & $\mathrm{~m} / \mathrm{s}$ \\
\hline Cut-out wind speed & 11 & $\mathrm{~m} / \mathrm{s}$ \\
\hline Survival wind speed & 30 & $\mathrm{~m} / \mathrm{s}$ \\
\hline Rated rotor power & 350 & $\mathrm{~W}$ \\
\hline Rated TSR & 5 & - \\
\hline Rated rotational speed & 500 & $\mathrm{rpm}$ \\
\hline Rated rotor torque & 6.2 & $\mathrm{Nm}$ \\
\hline
\end{tabular}

\section{Aerodynamic design}

The aerodynamic part of the design process involved complex blade and rotor geometry design and analysis, based on the design originally introduced by the team of Professor Lars Sætran (NTNU) [6]. As a result of the differences in rotor diameters, the geometry was scaled by a factor defined as a ratio between modified and original rotor radius. The main criterion considered during the design process was to maximize the Annual Energy Production (AEP). Having the wind conditions imposed, the whole construction needed to be adjusted to the specific parameters. The geometry was oriented at lowering cut-in wind speed, increasing the power coefficient and widening the operational range of the Tip Speed Ratios.

An initial part of the procedure was the airfoil selection. Due to a scale factor influence the existing geometry needed to be examined in terms of aerodynamics and material durability. Two substitutional numerical methods (ANSYS CFX and FAST) were used to calculate the turbine's performance, both of them implementing Blade Element Momentum theory.

In order to properly consider the air movement around the airfoil it was necessary to estimate the Reynolds numbers in particular cross-sections:

$$
\operatorname{Re}=u c_{i} / v_{\mathrm{air}},
$$

where $c_{i}$ denotes the assumed chord length of a specific cross section, $v_{\text {air }}$ is the kinematic viscosity of the air and $U_{\text {rated }}$ represents the vector sum of axial wind speed and rotational speed of the blade element on the analysed radial position. In order to simplify the analysis the induced velocity is not taken into account. The evaluation resulted in Reynolds number values within the range of $50000 \div 150000$. Further analysis and the validation process depended on data acquired from XFoil polars (see Figures 2 and 3) [7].

The blade geometry was originally entirely built on NREL S826 airfoil [8], which after taking the size factor into account invariably displayed the highest lift-to-drag ratio. Therefore, midspan and tip cross-sections remained unchanged regarding the airfoil shape. Significant modifications needed to be made in the sections located closest to the hub. Decreasing the chord length resulted in reduced stiffness of the blade root so that a thicker airfoil needed to be implemented there. The NREL S822, S823, S834 was examined to reinforce above mentioned location of the blade. The $\mathrm{S} 834$ airfoil was chosen because of the maximum value of $C_{L}$ to $C_{D}$ ratio among the above mentioned airfoils (see Table 2.).

The obtained blade design was validated in a series of numerical simulations. The analysis was carried out using FAST software for the whole operational range of wind speeds and the Tip Speed Ratio values between 2 and 7 .

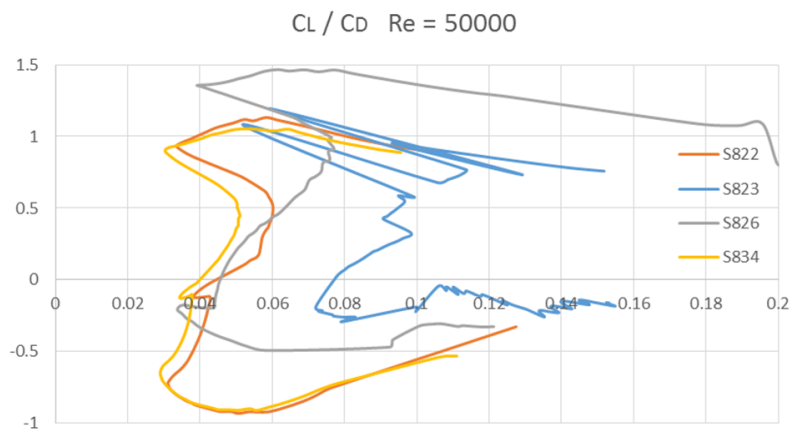

Fig. 2. Polar diagrams of four studied airfoil profiles with $R e=50000$.

$$
\mathrm{CL} / \mathrm{CD} \quad \mathrm{Re}=100000
$$

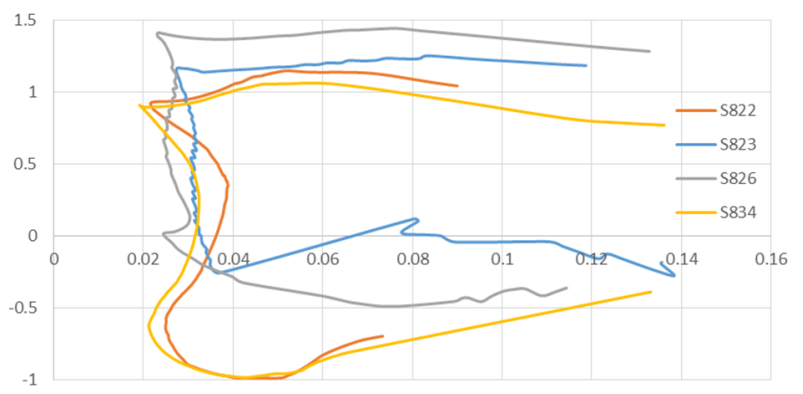

Fig. 3. Polar diagrams of four studied airfoil profiles with $R e=100000$.

Table 2. Summary of performance parameters of studied airfoils.

\begin{tabular}{|c|c|c|c|c|}
\hline & $\mathbf{S 8 2 2}$ & $\mathbf{S 8 2 3}$ & $\mathbf{S 8 2 6}$ & $\mathbf{S 8 3 4}$ \\
\hline $\max _{L} / C_{D}$ & 42.84 & 42.52 & 60.72 & 47.42 \\
\hline $\mathrm{AoA}^{\circ}$ & 8.4 & 9.1 & 8.3 & 7.1 \\
\hline$C_{L}$ & 0.921 & 1.157 & 1.409 & 0.909 \\
\hline$C_{D}$ & 0.022 & 0.027 & 0.023 & 0.019 \\
\hline
\end{tabular}

\section{Mechanical design}

The main tasks of the mechanical design were to:

- Choose appropriate materials for elements,

- Connect generator shaft with the blades (via hub),

- Mount other components of the small wind turbine (like encoder and brake discs),

- Design brake and yaw systems,

- Evaluate stresses in the most vulnerable elements.

The element subjected to the stresses was the hub, which also had to have possibly low moment of inertia so it was chosen to use PA6 aluminum alloy. The blades have to be lightweight but it must also be possible to produce a complicated shape of the blades with a possibly low cost. Technologies like CNC milling and SLS- or SLA 3D printing were considered. Finally, the last method was chosen because SLA 3D printing was as accurate as SLS technology; moreover, it was the most economical 
method. As a material, Protogen White (ABS-like, liquid photopolymer) was chosen. Also parts where stresses are negligible (nacelle, spinner) were 3D printed (less expensive FDM technology) [9].

The shaft of the generator on the rotor side had a keyset. At the end of it a screw with washer were screwed to prevent the hub from axial displacement. The hub was fabricated using CNC machine, which made it possible to get complicated shapes and reduced mass. The blades are mounted in the asymmetric cuts (which prevent improper assembly) using four screws put in the holes in the blades and in the hub. The brake and encoder discs are mounted on the sleeve with a collar placed on the shaft at the second end of the generator. (see Figures 4-6).
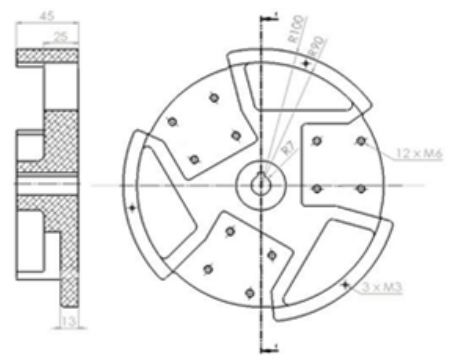

Fig. 4. Rotor hub: cross-section view (left), front view (right).

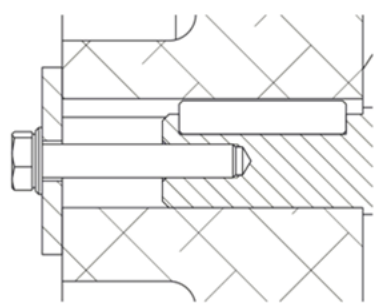

Fig. 5. Hub mounting.

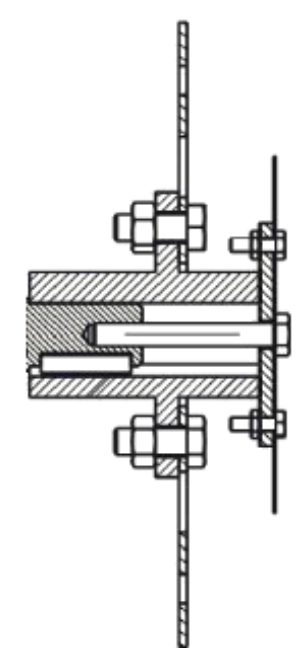

Fig. 6. Brake and encoder disc mounting.

As a brake was chosen a disc brake, which has low moment of inertia. The brake is controlled by a linear actuator through a hydraulic system. The dimensions of the hydraulic systems were calculated assuming that the volume of the hydraulic fluid is constant and its pressure is the same in all places of the hydraulic system [10]. The brake consists of a few simple-shaped elements. Drawings of the brake are presented in Fig. 7. and Fig. 8.

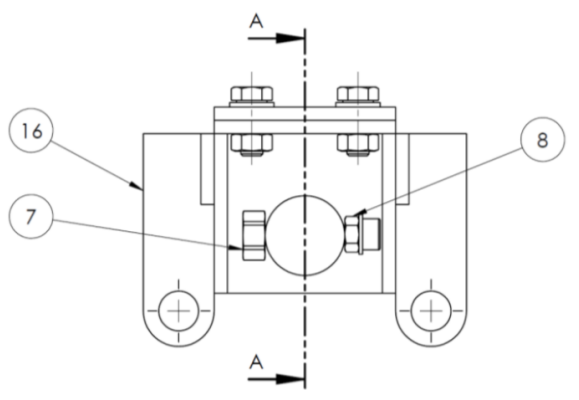

Fig. 7. Designed brake - side.

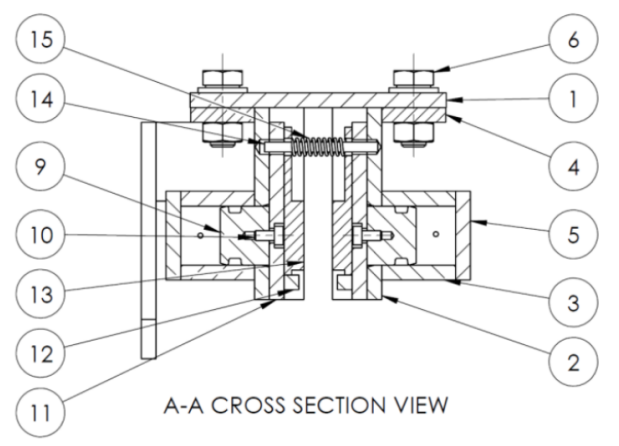

Fig. 8. Designed brake - section.

The yaw system, which adjusts the turbine position in the wind direction, includes the turntable and the tail. The tail was set perpendicularly to the rotor. When exposed to the wind stream, the tail spins into a position parallel to the wind direction. The turntable enables the turbine to rotate thanks to the bearings placed in it. The slip rings were also placed in the turntable to transmit the power from a rotating nacelle outside the turbine (Fig 9.) [11].

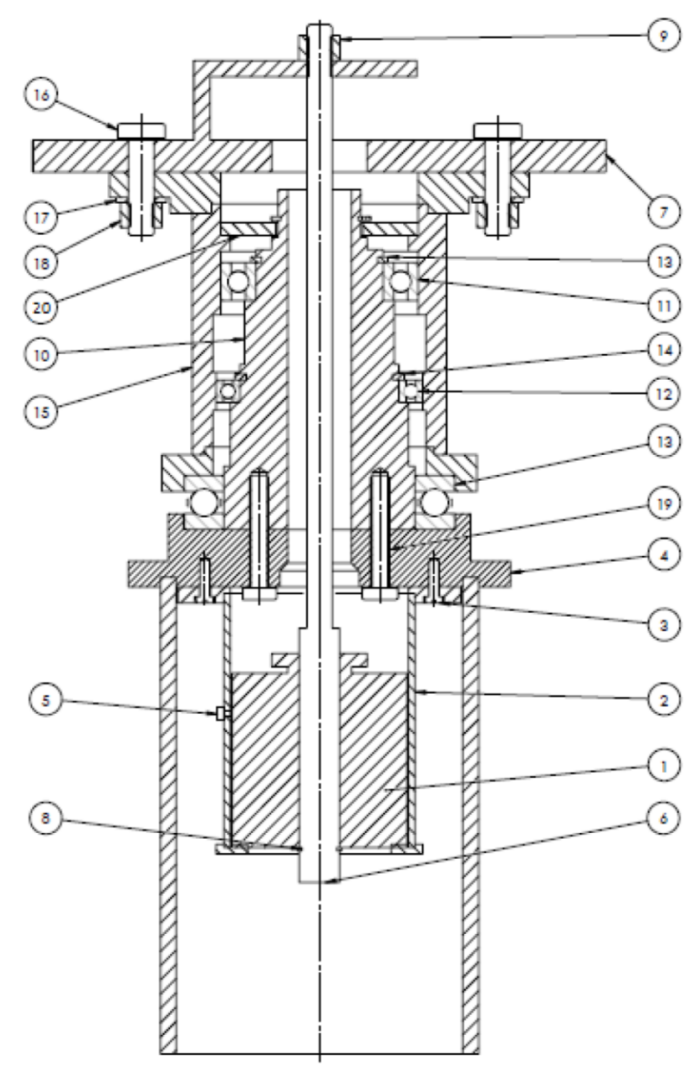

Fig. 9. Designed brake - section. 
Blades stresses were assessed using the Simple Load Model. It is presented in the International Electrical Committee (IEC) 61400-2 standard and is applicable for horizontal axis machines with rated power below $50 \mathrm{~kW}$. In all analysed loading conditions described in IEC standard designed turbine has not exceeded permitted values.

\section{Generator}

The electric generator is a device that makes the conversion from mechanical energy to electrical energy. Handling the intermittency of wind and maintaining the grid reliability are the most important points of small wind turbine generator development [12]. Because of insufficient resources for buying new generator it was decided to use one that was in stock of Institute of Turbomachinery, Lodz University of Technology. The main problem of that solution was that there was no information about its parameters. The test of Power and Torque versus RPM was made using the setup presented in Fig 10.

The generator was driven by a motor with controlled rotational speed measured by the RPM-counter. Also current and voltage were measured. The obtained results were used to create the power (Fig. 11) and torque (Fig. 12) functions.

The power of the tested generator reached around $400 \mathrm{~W}$ and the highest torque was around $6 \mathrm{Nm}$, which means that the generator is acceptable for usage in turbine design conditions.

\section{Safety systems}

Safety of the proposed SWT design is a crucial part of the construction and a lot of effort was exerted in order to propose a solution that would meet the requirements stated by the organizers of the ISWT Contest 2017. The safety system should:

- be independent and serve as a superior automatic protection for the turbine from single failures or faults in any component within the control system and from faults in the load connection;

- prevent the rotational speed and produced power from exceeding design limits for all load cases;

- allow the turbine to be stopped manually (remotely from at least a distance of $10 \mathrm{~m}$ ) in case of emergency and keep the rotor blocked;

- be integrated within the interface boundaries.

The main requirement for safety system was to design it without overcomplicating it. Simplicity is an advantage because it helps to reduce the number of the potentially weakest links in the system.

The following components make up the prototype of the safety system:

- Microcontroller with an independent battery and charging system;

- RPM and voltage / current monitoring sensor;

- Servomotor for brake actuation;

- Main battery serving as energy buffer for braking system;
- Simple data logger with micro SD card;

- Manual emergency button;

- Set of LEDs.

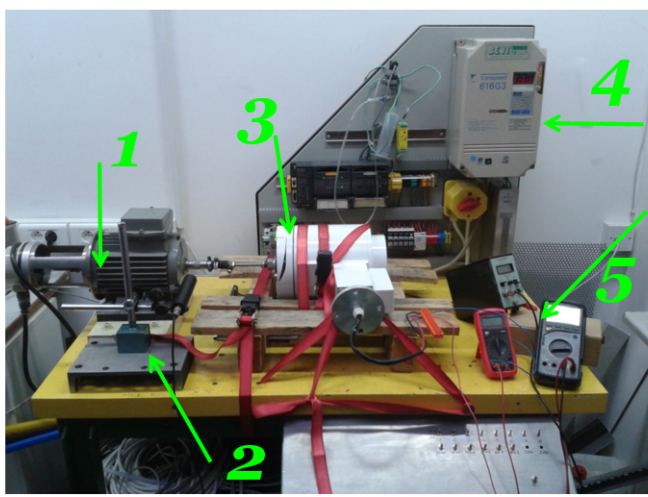

$$
\begin{aligned}
& \text { 1. Driving motor } \\
& \text { 2. RPM - counter } \\
& \text { 3. Investigated generator } \\
& \text { 4. Inverter } \\
& \text { 5. Digital multimeters (A, V, RPM) } \\
& \text { 6. Resistor (electric load) }
\end{aligned}
$$

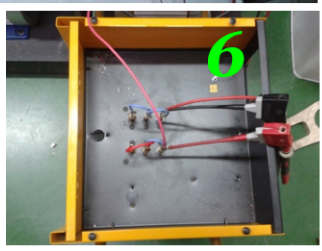

Fig. 10. Test setup for collecting generator power and torque characteristics.

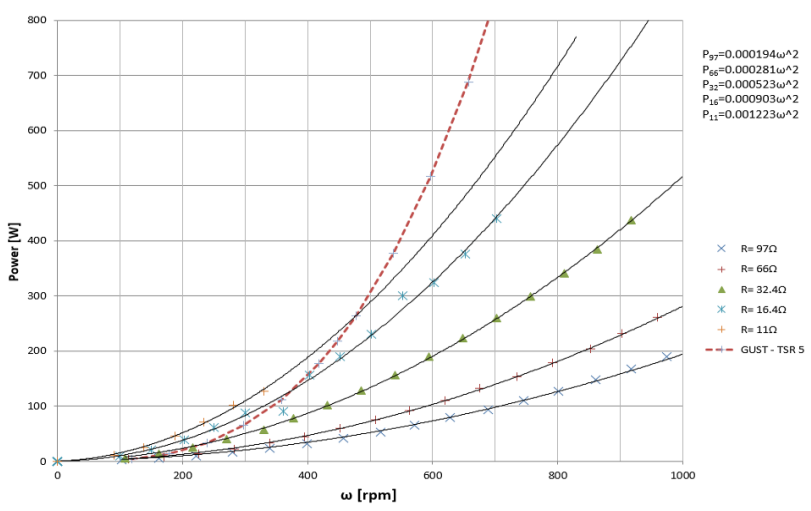

Fig. 11. Results of power vs RPM measurements of the generator supplemented with designed SWT power curve for optimal design $\mathrm{TSR}=5$.

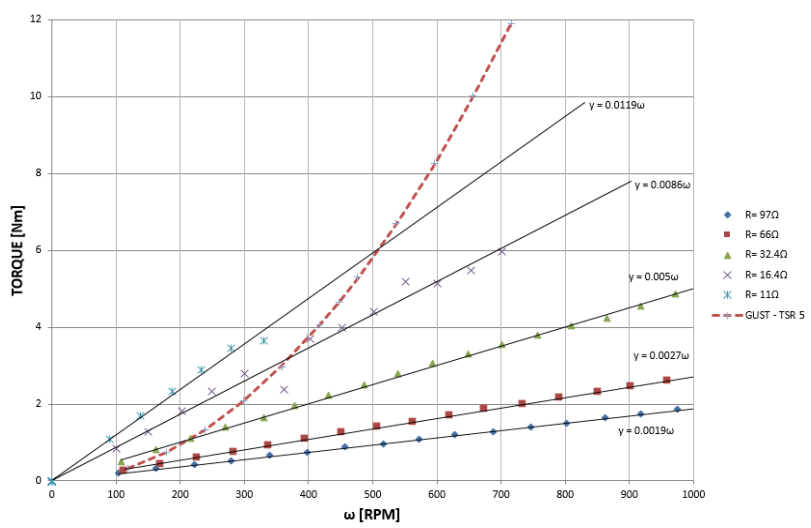

Fig. 12. Results of torque vs RPM measurements of the generator supplemented with designed SWT torque curve for optimal design $\mathrm{TSR}=5$.

The flow chart illustrating the logic of the whole control system and how it is managed via the microcontroller is presented in Fig. 13. 


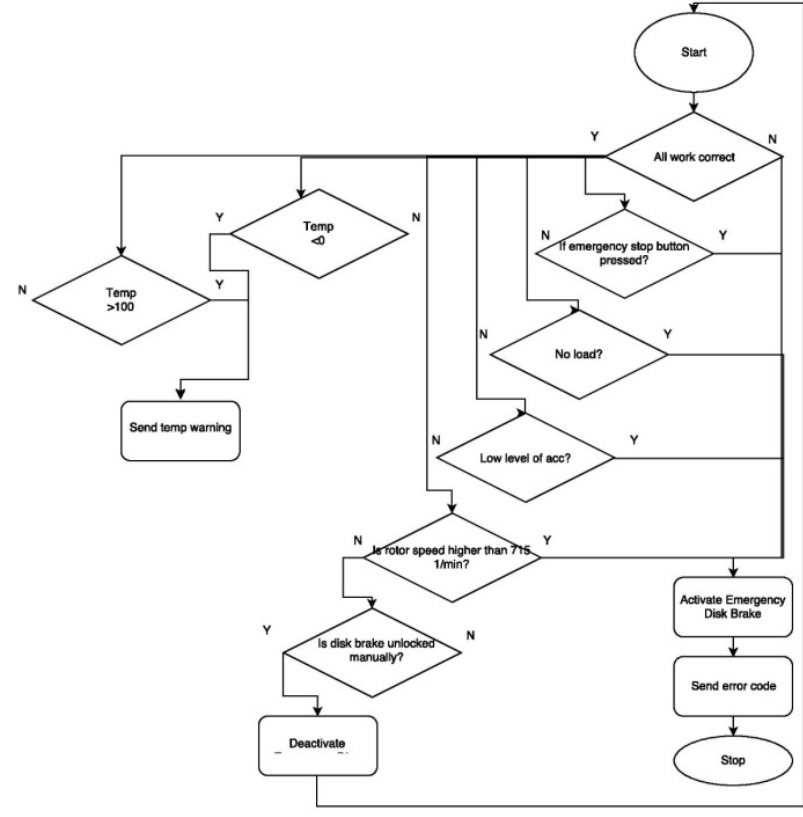

Fig. 13. Flow chart showing the proposed operational procedure for microcontroller.

As a microcontroller, which serves as a superior controller for the entire system, the Arduino pro mini 328 $3.3 \mathrm{~V} 8 \mathrm{MHz}$ was chosen, one of the most common solutions in these applications [13]. It may be easily programmed via USB, serves both digital (RPM sensor) as well as analog inputs (voltage measurement with a use of simple amplifier). Arduino would be equipped with an independent battery (Li-Po 3.7V) and charging system that would replenish its energy level from the main battery if it drops below a certain fixed level. The safety level was set at 50 percent of the total controller battery capacity.

At first the microcontroller checks whether all the sensors are active and then if any of measured parameter is not off the limit. For example checks if high temperature of the electronic system is detected that may lead to its malfunction. This might happen if the machine is exposed to sunlight on a scorching day for too long. Simultaneously, the controller checks if the manual emergency button is pressed or if there is enough energy stored in order to keep the electronics running. If any of the above conditions is not met the emergency brake will be activated preventing the turbine from starting to spin. This action is signalled by turning on an adequate LED in order to inform the users about the fault.

The same will happen if the maximum rotational speed of 800 RPM is exceeded or the voltage monitoring sensor indicates lack of load. The servomotor will start to clamp the actuators on the brake disc and bring it to stop. In order to unblock the rotor, the operator has to do it manually (using a remote control system - one featuring an emergency button).

Additionally, a measured data acquisition system was installed. For this task, a data logger with micro SD slot was used in the control system. For example, a record of the rotational speed measurement by a photo interpreter located just behind the brake disc is saved in the mentioned memory card.

\section{Conclusions}

The prototype of a small wind turbine, whose design was presented in this paper, was built and tested in the aerodynamic tunnel in Delft University of Technology, the Netherlands. The results of the test showed that all systems of the prototype worked properly, but there were some aspects that still needed improvement.

The first one was to design a system which would permit to adjust the aerodynamic power curve to the electrical power curve to increase the efficiency of producing electrical energy.

The second one was to decrease the inertia of the rotor and friction in the bearing system to decrease the cut-in wind speed.

The last one was to improve the control and safety system to make it possible to collect information from the sensors and save it in the cloud to have the possibility to access that information online.

\section{References}

1. WindEurope, Wind in power 2017, Annual combined onshore and offshore wind energy statistics, windeurope.org, Brussels, Belgium, (2018)

2. I.61400-2, Wind turbines - Part 2: Design requirements for small wind turbine (2006)

3. A. Tummala, R. Velamati, D. Sinha, V. Indraja, V. Krishna, A review on small scale wind turbines, Renew. Sustain. Energy Rev., 56, 1351-1371 (2016)

4. http://www.iswtc.com/ (28.07.2018)

5. P. Gipe, Wind energy for the rest of us: a comprehensive guide to wind power and how to use it, (Bakersfield, CA: wind-works.org, 2016)

6. L. Sætran, J. Bartl, Invitation to the 2015 "Blind test 4" Workshop, Technical document NTNU, www.sintef.no/globalassets/project/nowitech/events/ bt4_invitation2015.pdf (15.07.2018)

7. M. Drela, XFOIL: An analysis and design system for low Reynolds number airfoils. Low Reynolds number aerodynamics. Lecture Notes in Engineering, 54 (Springer, Berlin, Heidelberg 1989)

8. https://wind.nrel.gov/airfoils/AirfoilFamilies.html (18.07.2018)

9. K. Olasek, P. Wiklak, Application of 3D printing technology in aerodynamic study, J. Physics: Conference Series, 530 (2014)

10. D. Elger, B. Williams, C. Crowe, J. Roberson, Engineering Fluid Mechanics, 1-692 (2013)

11. L. Kurmaz, Projektowanie węzłów i części maszyn, Kielce, Poland, 1-449 (2007)

12. M. Hosain, M. Ali, Future research directions for the wind turbine generator system, Renewable and Sustainable Energy Rev., 49, 481-489 (Elsevier, 2015)

13. F. Mahmuddin, A. Yusran, S. Klara, On the use of an Arduino-based controller to control the charging process of a wind turbine, AIP Conference Proceedings, 1814(1) (2017) 